\title{
Complete Pattern of Ocular Dominance Columns in Human Primary Visual Cortex
}

\author{
Daniel L. Adams, Lawrence C. Sincich, and Jonathan C. Horton \\ Beckman Vision Center, Program in Neuroscience, University of California, San Francisco, San Francisco, California 94143-0730
}

The occipital lobes were obtained after death from six adult subjects with monocular visual loss. Flat-mounts were processed for cytochrome oxidase (CO) to reveal metabolic activity in the primary (V1) and secondary (V2) visual cortices. Mean V1 surface area was $2643 \mathrm{~mm}^{2}$ (range, 1986-3477 $\mathrm{mm}^{2}$ ). Ocular dominance columns were present in all cases, having a mean width of $863 \mu \mathrm{m}$. There were 78-126 column pairs along the V1 perimeter. Human column patterns were highly variable, but in at least one person they resembled a scaled-up version of macaque columns. CO patches in the upper layers were centered on ocular dominance columns in layer $4 \mathrm{C}$, with one exception. In this individual, the columns in a local area resembled those present in the squirrel monkey, and no evidence was found for column/patch alignment. In every subject, the blind spot of the contralateral eye was conspicuous as an oval region without ocular dominance columns. It provided a precise landmark for delineating the central $15^{\circ}$ of the visual field. A mean of $53.1 \%$ of striate cortex was devoted to the representation of the central $15^{\circ}$. This fraction was less than the proportion of striate cortex allocated to the representation of the central $15^{\circ}$ in the macaque. Within the central $15^{\circ}$, each eye occupied an equal territory. Beyond this eccentricity, the contralateral eye predominated, occupying $63 \%$ of the cortex. In one subject, monocular visual loss began at age 4 months, causing shrinkage of ocular dominance columns. In V2, which had a larger surface area than V1, CO stripes were present but could not be classified as thick or thin.

Key words: cytochrome oxidase; cortical magnification factor; visual field; retinotopic map; flat-mount; V1; V2; amblyopia

\section{Introduction}

To understand binocular integration in the human brain, it is vital to have a clear description of how inputs serving each eye are united in the primary visual cortex (V1). Hubel and Wiesel (1969) showed in the macaque that the axon terminals of cells in the lateral geniculate nucleus are not randomly distributed in layer 4C. Instead, they are clustered into alternating bands, called ocular dominance columns, serving either the right eye or the left eye. In animals, these columns can be labeled by injection of a tracer such as $\left[{ }^{3} \mathrm{H}\right]$ proline into one eye (Wiesel et al., 1974). The tracer is taken up by retinal ganglion cells and conveyed to the lateral geniculate nucleus. After crossing the retinogeniculate synapse, $\left[{ }^{3} \mathrm{H}\right]$ proline is transported to striate cortex. This technique has been used successfully to reveal ocular dominance columns in many species (for review, see Horton and Hocking, 1996a).

The ocular dominance columns can also be identified by processing the cortex for cytochrome oxidase (CO) after monocular enucleation (Wong-Riley, 1979). The columns of the missing eye appear pale because their metabolic activity is reduced. It has been shown, by combining $\mathrm{CO}$ histochemistry and $\left[{ }^{3} \mathrm{H}\right]$ proline autoradiography in the same animal, that both techniques yield

\footnotetext{
Received Jan. 17, 2007; revised Aug. 3, 2007; accepted Aug. 6, 2007

This work was supported by National Eye Institute Grant R01 EY10217 and Core Grant EY02162. We thank the subjects and their surviving family members.

Correspondence should be addressed to Jonathan C. Horton, 10 Koret Way, University of California, San Francisco, San Francisco, CA 94143-0730. E-mail: hortonj@vision.ucsf.edu.

DOI:10.1523/JNEUROSCI.2923-07.2007

Copyright $\odot 2007$ Society for Neuroscience $\quad$ 0270-6474/07/2710391-13\$15.00/0
}

an identical pattern of ocular dominance columns (Horton, 1984; Sincich and Horton, 2002). Consequently, CO histochemistry can be used as a valid substitute for transneuronal $\left[{ }^{3} \mathrm{H}\right]$ proline to identify ocular dominance columns.

The enormous advantage of $\mathrm{CO}$ histochemistry is that it can be used to probe patterns of metabolic activity in the human brain for several days after death. After a Glees silver stain showed suggestive bands in layer 4A (Hitchcock and Hickey, 1980), the existence of ocular dominance columns in the human was proven by staining the cortex for $\mathrm{CO}$ in subjects with monocular blindness (Horton and Hedley-Whyte, 1984; Horton et al., 1990). In these early studies, only a few subjects were examined. Because of the size and convolutions of the human cortex, only fragments of the column pattern were reconstructed. In recent years, techniques for flat-mounting the cerebral cortex have made it possible to reconstruct column patterns over wider expanses of tissue (Horton, 1984; Olavarria and Van Sluyters, 1985; Tootell and Silverman, 1985; Lowel and Singer, 1987; Rosa et al., 1988; Florence and Kaas, 1992; Tootell and Taylor, 1995; Sincich et al., 2003).

Here we describe the ocular dominance columns in flatmounted specimens of human striate cortex. Six cases have been reconstructed completely, allowing assessment of intersubject variability in column morphology and periodicity. Fourier analysis showed that the columns are much larger and more variable in spacing in the human compared with the macaque. Rows of $\mathrm{CO}$ patches in the superficial layers were aligned with the ocular dominance columns in layer 4C. However, in one subject, this correlation was lost in a region of the cortex in which the columns assumed an anomalous appearance. In the macular representa- 
tion, columns serving each eye occupied equal surface area, but, beyond $15^{\circ}$, the columns of the contralateral eye filled more territory. In humans, a smaller percentage of striate cortex was devoted to the representation of the central $15^{\circ}$ than in the macaque. In one subject, visual deprivation occurred during the critical period, resulting in shrinkage of the ocular dominance columns.

\section{Materials and Methods}

Cortical flattening. The occipital lobes and remaining eye were obtained from six subjects of European descent with a history of monocular visual loss. They were patients of one of the authors (J.C.H.). Each patient, or surviving next-of-kin, provided written permission for postmortem histological examination, following a protocol approved by an Institutional Review Board. In every subject, except case 6, the eye was enucleated during adulthood. The time period between enucleation and death ranged from $5 \mathrm{~d}$ to 22 years. In each subject, except case 6 , normal visual function was documented in each eye before the onset of vision loss.

The time between death and tissue removal ranged between 4 and $9 \mathrm{~h}$. Best results were obtained when the brain was removed as soon as possible after death, and the dissection was started immediately. First, blood vessels and pia were stripped off the surface of the cortex, allowing the sulci to open and fixative to circulate evenly. Intermittently, the dissection was interrupted to immerse the tissue in chilled $1 \%$ paraformaldehyde in $0.1 \mathrm{M}$ phosphate buffer. Fixation was required to harden the cortex so that it could be handled during the dissection process. Typically, it required $10-14 \mathrm{~h}$ to flatten a single hemisphere. Afterward, the tissue was postfixed in $1.5 \%$ paraformaldehyde plus $30 \%$ sucrose for $\sim 12$ h. The flat-mount was then cut tangentially on a freezing microtome at $60 \mu \mathrm{m}$, and serial sections were processed for CO using techniques described previously (Sincich et al., 2003).

Computerized montaging. Sections were scanned at $600 \mathrm{dpi}$ on a flatbed scanner with a transparency adapter (Epson Expression 1680). Images were imported into Matlab (MathWorks, Natick, MA) for alignment of adjacent sections. The mounting of large $(10 \times 14 \mathrm{~cm})$ sections from aqueous solution to glass slides slightly distorts each sheet of tissue in a different manner. To surmount this problem, large blood vessels were used as fiduciary marks for alignment of adjacent flat-mount sections. They are ideal for this purpose because they run perpendicular to the pial surface. Using the image registration function (Matlab 7.0 Image Processing Toolbox), $\sim 80-100$ evenly distributed blood vessel profiles were identified in adjacent sections as control points. Then, a rigid transformation was applied to align all the sections, minimizing differences caused by translation or rotation between sections (Video 1, http://www. ucsf.edu/hortonlab/movies.html). Next, a template section was chosen from the middle of the cortex. Other sections were brought into precise register with the template by transforming them with the local weighted mean setting, essentially custom warping them to fit the template using the blood vessels as a guide. This process was performed in a pairwise manner for all sections above and below the unwarped template (Video 2, http://www.ucsf.edu/hortonlab/movies.html). This eliminated idiosyncratic distortion caused by local stretching of the tissue during mounting of individual sections.

Transformed section images were imported subsequently into a single Adobe Photoshop file (Adobe Systems, San Jose, CA), with each section placed in a dedicated layer. The image stack was ordered serially with the deepest section in front. Then a "transparency mask" was applied to each layer. Starting with the deepest section, the cortical layers below $4 \mathrm{C} \beta$ were masked out by hand. This process was then repeated with each subsequent section to systematically compile a complete montage of layer $4 \mathrm{C} \beta$. Approaching $4 \mathrm{C}$ from the infragranular side was optimal, because the sharp transition in $\mathrm{CO}$ density from layer 5 to layer $4 \mathrm{C} \beta$ was easy to recognize. This ensured that only $4 \mathrm{C} \beta$ was used to construct the montage. It was important to avoid $4 \mathrm{C} \alpha$ because the columns have less $\mathrm{CO}$ contrast in this sublayer. After the montage was finished, brightness and contrast were optimized for each section independently, by means of a separate adjustment for each layer. A Gaussian blur (size of three pixels) was applied to the edges of the transparency masks to minimize the visibility of transitions between different sections in the montage. Finally, the individual layers were merged into a single image, and a filter ("dust and scratches") was applied to minimize the visibility of blood vessels and minor imperfections.

Montage analysis. Ocular dominance columns were rendered by highpass Fourier filtering the montage to reduce fluctuations in density caused by slight variations in section thickness or depth within layer $4 \mathrm{C} \beta$. The filtered image was then blurred with a Gaussian kernel to eliminate high-frequency components. A binary map of the ocular dominance columns was produced by applying a density threshold to the image at the modal gray value. To measure the column areas, the binary map was placed on a gray background. The number of black and of white pixels (each measuring $42 \times 42 \mu \mathrm{m}$ ) was counted. The column maps were divided into macular and peripheral regions by plotting an isoeccentricity line that bisected the representation of the blind spot.

Wavelet analysis provides an elegant means to extract information about column spacing and local anisotropy, i.e., whether columns are patchy or band like (Kaschube et al., 2002). An alternative approach, which we elected, is to use Fourier analysis (Swindale, 1988; Obermayer and Blasdel, 1993). To obtain a measure of column width, the radial sum of a two-dimensional Fourier spectrum of the binary column map was plotted using a custom analysis tool in Matlab (see Fig. 6). Spectra were acquired for each human hemisphere and compared with spectra compiled from column patterns reconstructed in previous studies of normal macaques and squirrel monkeys. The wavelength of the spectrum peak for each plot was taken as a measure of typical column width. Values for the left and right hemispheres from individual subjects were averaged, and the mean value was used to compare human and macaque column widths. To derive another index of column width, the number of columns intersecting the V1/V2 border was counted and divided by the length of the binocular perimeter. All data are reported as mean \pm SD.

Spatial averaging. The relationship between patches and columns can be quantified by measuring the distance from patch centers to column borders (Hübener et al., 1997; Duffy et al., 2007). However, patches in humans are less punctate than in macaques or squirrel monkeys. Consequently, the center alone is less useful for defining the location of a patch than an algorithm that incorporates information about the entire structure. For this reason, we performed a spatial correlation to quantify the relationship between patches and ocular dominance columns (Lia and Olavarria, 1996; Boyd and Casagrande, 1999; Adams and Horton, 2006b). To define patches, a single CO section was high-pass Fourier filtered to correct for global changes in section density (attributable to small differences in layer 3 depth). The resulting image was then blurred with a Gaussian filter $(\sigma=35 \mu \mathrm{m})$ to eliminate blood vessels. It was thresholded by assigning to black (grayscale value of 0 ) all pixels darker than the modal value. All remaining pixels were assigned to white (grayscale value of 1 ).

The borders of the ocular dominance columns in montages of layer $4 \mathrm{C} \beta$ from the identical region were defined using the Canny edge detector (Canny, 1986) implemented in Matlab. A spatial correlation was then computed between $\mathrm{CO}$ patches and column borders in multiple regions of cortex from each subject (for examples, see Figs. 8, 9). This was done by averaging images of the borders (one pixel thick) of the ocular dominance columns centered on each pixel in every patch within a field measuring $144 \mathrm{~mm}^{2}$. The ocular dominance column border image measured $2.2 \mathrm{~mm}$ per side, which corresponds to more than a column pair. This process produced an average border image that showed the relationship between each patch pixel and each ocular dominance column border pixel. As a control, the same spatial correlation was performed with the ocular dominance column border pattern rotated $90^{\circ}$ with respect to the patch image. The distribution of pixel values in the spatial correlations reflects the presence or absence of a consistent relationship between patches and column borders. Aligned and rotated spatial correlations were normalized by shifting their mean values to the middle gray level and then multiplying each by the same constant to expand the grayscale maximally. The variance in grayscale values of the image pixels was compared statistically with Levene's test to detect equal variance.

Figure 9 shows a case in which the cross-correlation between patches and columns failed to show any relationship. To reduce the possibility 
that this negative result might have been attributable to the montaging process, we also performed the analysis using single, unmontaged sections. Two approaches to section alignment were tried: rigid translation/ rotation and local vessel warping. We also aligned the column montage with the upper layer section using only rigid translation/rotation. None of these approaches produced any evidence of a correlation in this particular case.

\section{Results}

\section{Complete pattern of human ocular dominance columns}

The pattern formed by the ocular dominance columns was reconstructed in five subjects who lost vision in one eye during adulthood. Figure 1 shows the process of preparing a flat-mount in case 2, a 79-year-old man who became blind in his left eye 1 year before his death. The entire calcarine sulcus was dissected from the underlying white matter, transforming the medial face of the intact right occipital lobe into a sheet of tissue $\sim 2-3 \mathrm{~mm}$ thick with a surface area of $9413 \mathrm{~mm}^{2}$. This block $(14 \times 10 \mathrm{~cm}$, maximum dimensions) was the largest that could be cut on the rectangular stage of the freezing microtome as a single piece of tissue. It was equal to $\sim 10 \%$ of the surface area of a human cortical hemisphere.

Figures 2 and 3 show complete montages of the ocular dominance columns from each occipital lobe, prepared from fragments of layer $4 \mathrm{C} \beta$ contained in 27 serial $60 \mu \mathrm{m}$ CO sections. The surface areas of the right and left primary visual cortices were 2878 and $2625 \mathrm{~mm}^{2}$, respectively. In this subject, the columns were reminiscent of those found in the macaque, but they were thicker and less stripe-like. The peak in the radially summed Fourier power spectrum was taken as a measure of typical column width. It was $960 \mu \mathrm{m}$ in the right hemisphere and $995 \mu \mathrm{m}$ in the left hemisphere (Table 1). Along the V1 border, there were 189 columns on the right side (binocular perimeter of $187 \mathrm{~mm}$ ) and 178 columns on the left side (binocular perimeter of $193 \mathrm{~mm}$ ) for a right mean column width of $992 \mu \mathrm{m}$ and a left mean column width of $1089 \mu \mathrm{m}$. These data reflect the fact that the columns become slightly wider along the V1/V2 border in the human, just as in the macaque (Horton and Hocking, 1996b).

The width of the ocular dominance columns was fairly uniform across the visual field representation in striate cortex, except near the monocular crescent representation, where the columns of the ipsilateral eye became attenuated and fragmented. The portion of the visual field served by each column, however, varied enormously as a function of eccentricity. In the macaque, this principle has been demonstrated by projecting the ocular dominance columns onto the visual hemifield (Hubel and Freeman, 1977; LeVay et al., 1985). To perform this operation in the human, visual field coordinates were derived from a previous study of cortical magnification factor, using the following expression: $M_{\text {linear }}=17.3(E+0.75)^{-1}$, where $M_{\text {linear }}$ is cortical magnification in millimeters per degree, and $E$ is eccentricity in degrees (Horton and Hoyt, 1991). Integration of this formula from $0^{\circ}$ to each eccentricity value yielded radii for a series of concentric arcs, each centered on the fovea. These arcs correspond to the isoeccentricity contours in the cortical map (Fig. 4, top). In the macaque, it has been shown that magnification along different isopolar contours is quite similar for each eccentricity range (Van Essen et al., 1984). Therefore, to plot the isopolar contours in the human map, it was assumed that cortical magnification along different isopolar contours is the same for any given eccentricity.

The pattern of ocular dominance columns in striate cortex was transferred onto the visual field by matching the intersection of each isopolar and isoeccentricity contour in the retinotopic map with its corresponding point in the visual field. A computer
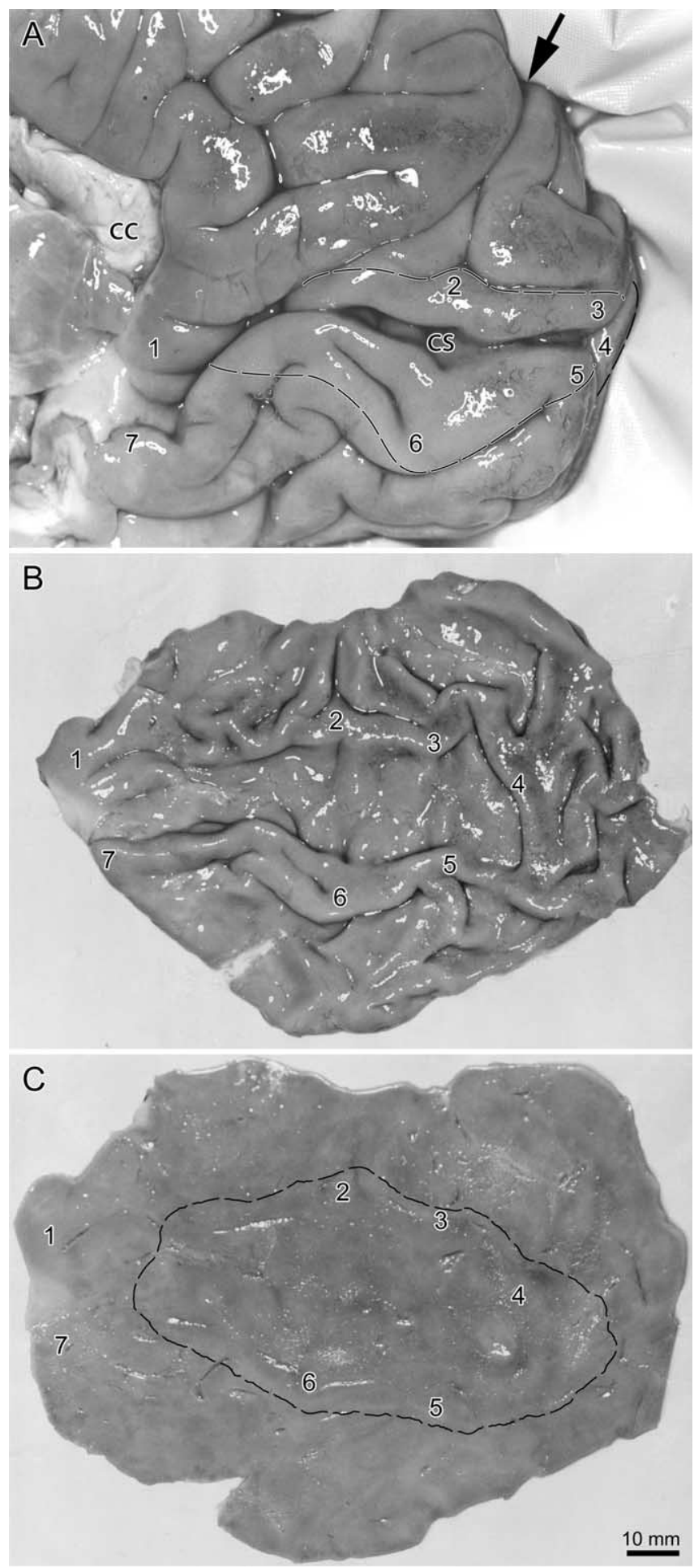

Figure 1. Preparation of flat-mounts from the human occipital lobe. $A$, Intact right occipital lobe from case 2, after removal of the leptomeninges, showing the medial face. The dashed line indicates the V1/V2 border, where it is visible on the surface of the brain. Arrow, Parietooccipital sulcus. cc, Splenium of corpus callosum; cs, calcarine sulcus. B, Midway through the dissection, showing the opened calcarine sulcus. The numbers denote corresponding locations in each image. C, Final flattened tissue block, ready to be frozen and cut with a microtome. The location of $\mathrm{V} 1$, determined later from $\mathrm{C} 0$-stained sections, is shown by the dashed line.

program was then used to transform the retinotopic map so that it fit the dimensions of the visual field (Video 3, http://www.ucsf. edu/hortonlab/movies.html) (Elastic Reality; Avid Technology, Tewksbury, MA). This process distorted the ocular dominance 
column pattern, showing directly the amount of visual field subtended by each column pair (Fig. 4, bottom). In the foveal representation, a column pair corresponded to $\sim 0.1^{\circ}$, whereas in the periphery, by comparison, a single column pair covered many degrees.

An intuitive sense of the effect of cortical magnification on the representation of the visual scene in striate cortex can be conveyed by performing the reverse transformation, namely, by translating objects in the visual field onto the retinotopic map (Schwartz, 1994). Sequential images obtained from a scan path, recorded while an author viewed a painting, show how the representation of the visual scene changes dynamically in the primary visual cortex (Video 4, http://www.ucsf.edu/hortonlab/ movies.html).

The columns tend to be oriented perpendicular to the vertical meridian (V1/V2 border) and to run parallel to isoeccentricity contours (Fig. 4, top). This arrangement may minimize distortion caused by gradients in cortical magnification. The vertical meridian was longer than the horizontal meridian, by a factor of 1.1 (upper vertical, $86 \mathrm{~mm}$; lower vertical, $88 \mathrm{~mm}$; horizontal meridian, $78 \mathrm{~mm}$; all measured from $0^{\circ}$ to $\left.64^{\circ}\right)$. Microelectrode studies in layer $4 \mathrm{C}$ of macaques have suggested that each set of columns contains a complete but fractured representation of the visual field (Hubel and Wiesel, 1977). Local cortical magnification factor is greater along columns than across them, because the visual field must be represented twice, independently by each eye (Horton, 1984; Anderson et al., 1988; Tootell et al., 1988; Blasdel and Campbell, 2001). Global distortion in the visual field representation caused by local anisotropy within individual columns may be reduced by deployment of the columns perpendicular to the vertical meridian. The greater length of the vertical meridian has the effect of partially compensating for the reduction of cortical magnification factor across columns.

\section{Quantitative comparison of ocular dominance columns in humans and macaques}

Figure 5 shows the complete pattern of ocular dominance columns from the right hemisphere of another human subject, case 5 . Her right eye was enucleated 10 years before death because of a choroidal melanoma. The total area of the primary visual cortex was $3477 \mathrm{~mm}^{2}$. Among all subjects, this individual's columns bore the closest resemblance to the columns found in the macaque. A typical macaque case, with a V1 surface area of $1127 \mathrm{~mm}^{2}$, is shown in Figure $5 C$. The mean column width in the macaque was $555 \mu \mathrm{m}$
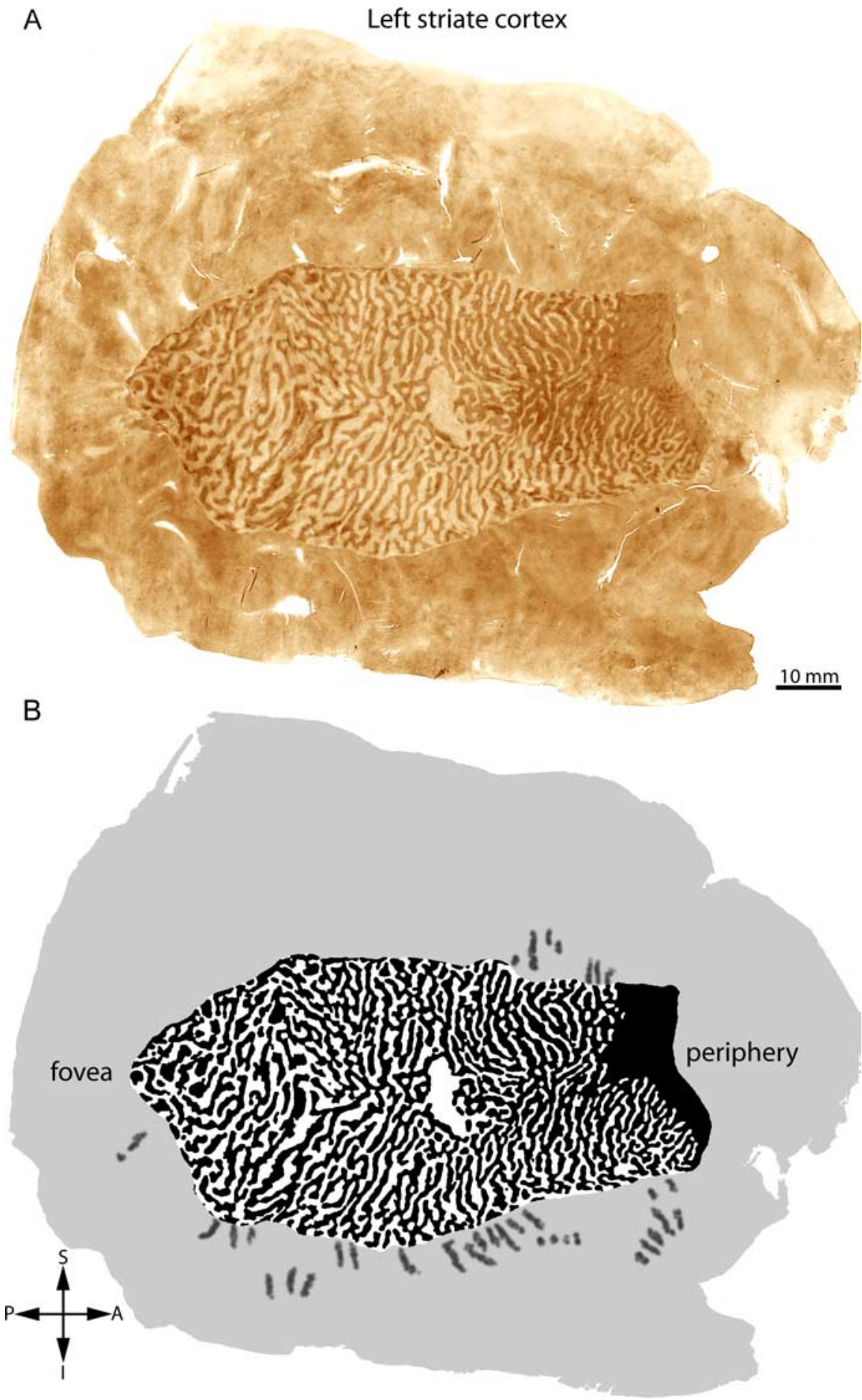

Figure 2. The complete pattern of ocular dominance columns in the human brain. $A, C O$ activity in layer $4 C \beta$ montage of the left primary visual cortex after loss of the left eye in case 2 . The $C 0$ pattern in V2 is a montage compiled from three sections passing through layer 4. The total area of the flat-mount is $10,117 \mathrm{~mm}^{2} . B, 0$ cular dominance columns rendered by high-pass Fourier filtering of the image in $\boldsymbol{A}$, followed by application of a threshold function (see Materials and Methods). Columns are absent in the blind spot and monocular crescent regions. S, Superior; $A$, anterior; $I$, inferior; $P$, posterior.

compared with $840 \mu \mathrm{m}$ in the human. For the sake of comparison, the scale in Figure $5 C$ has been adjusted so that the surface area of the macaque cortex is equal to the human cortex. There were 116 pairs of columns along the perimeter of $\mathrm{V} 1$ in the human case compared with 122 pairs in the macaque case. The human columns formed interdigitated bands with frequent bifurcations and blind endings. They were similar to the columns in 

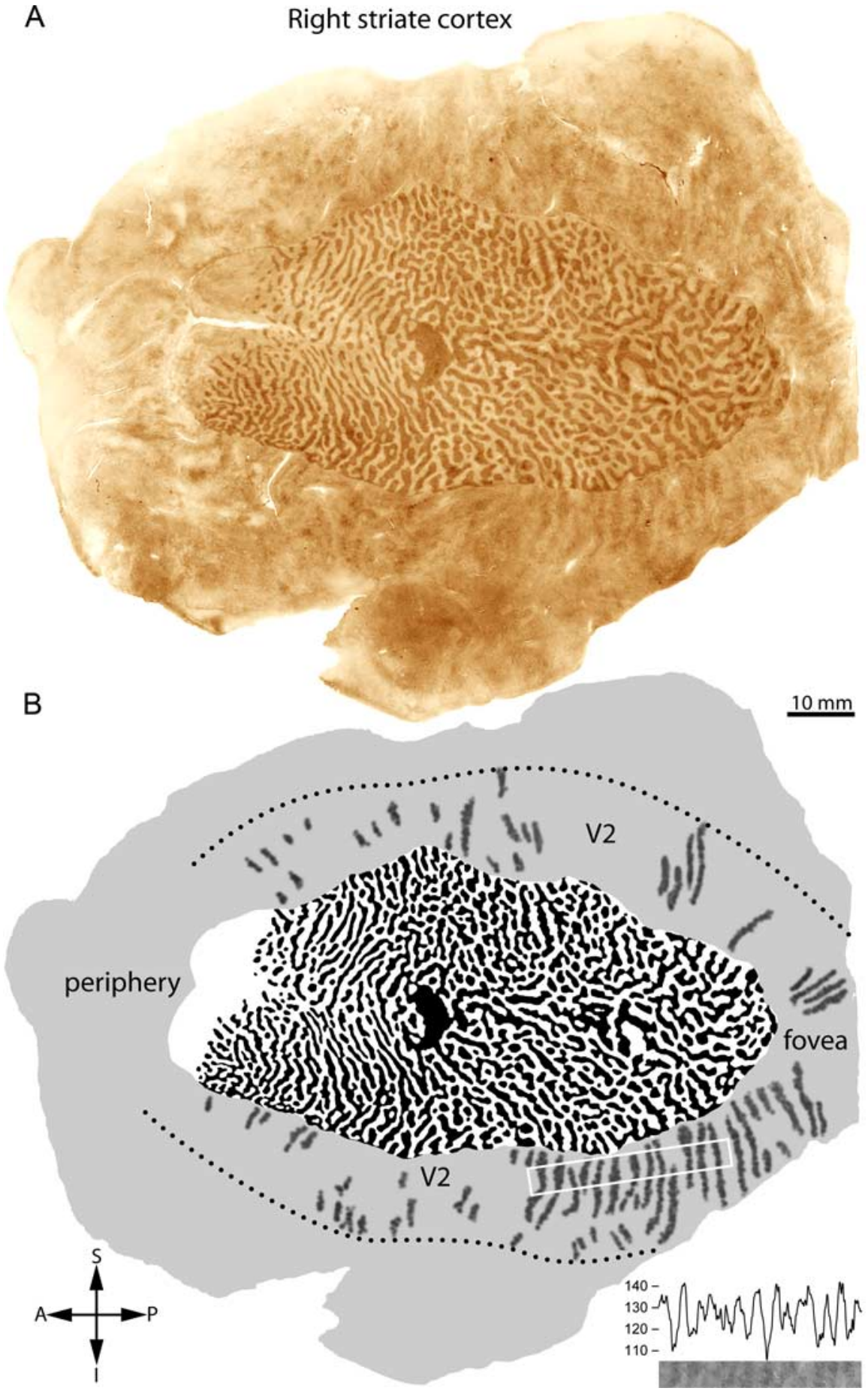

Figure 3. The complete pattern of ocular dominance columns in the human brain. $\boldsymbol{A}$, Corresponding right hemisphere from the case illustrated in Figure 2. The surface area of the flat mount is $9413 \mathrm{~mm}^{2}$. The V2/V3 border can be identified, based on a subtle change in the pattern of $\mathrm{CO}$ activity. Alternating dark and light stripes are visible in some portions of $\mathrm{V} 2$. Their density (see inset in B) fluctuated with an average period of $2.3 \mathrm{~mm}$. $\boldsymbol{B}$, Thresholded columns, processed as described in Figure $2 B$. Stripes were drawn where visible in V2; the white box shows where the $\mathrm{C} O$ density in $A$ was sampled to measure $\mathrm{V} 2$ stripe periodicity by counting the number of peaks. Dotted line indicates V2/V3 border. S, Superior; A, anterior; I, inferior; P, posterior.

the macaque example, following the same characteristic direction of flow in different regions of the cortex. These examples show that, at least in some human subjects, the columns are nearly indistinguishable from those found in macaques, except for the difference in scale. They also establish that the layout of the columns has nothing to do with the cortical gyri and sulci, because the occipital lobes in the human and the macaque are folded quite differently.

The data for all human subjects are summarized in Table 1. The mean area of striate cortex was $2643 \pm 476 \mathrm{~mm}^{2}$, with a range of 1986-3477 $\mathrm{mm}^{2}$. For comparison, measurements were compiled from column patterns reconstructed previously in 14 macaques (supplemental Table 1, available at www.jneurosci.org as supplemental material). The mean surface area of $\mathrm{V} 1$ in these 28 hemispheres was $1189 \mathrm{~mm}^{2}$ $\pm 188 \mathrm{~mm}$, with a range of $879-1646$ $\mathrm{mm}^{2}$. Thus, both species show nearly a twofold range in the surface area of $\mathrm{V} 1$ among normal subjects.

For the human subjects, the ocular dominance column widths ranged between 730 and $995 \mu \mathrm{m}$, with a mean of $863 \pm 102 \mu \mathrm{m}$, ascertained from the peak in the Fourier spectrum for each column montage (Fig. 6A). Fourier spectra from the left and right hemispheres from individual cases were closely paired, confirming a previous observation in macaques that column patterns in the two hemispheres from the same brain are similar (Horton and Hocking, 1996b). The average number of column pairs counted along the V1/V2 border was 100 , with a range of $78-126$ (Table 1 ). This yielded a mean single column width along the V1/V2 border of $948 \pm 123 \mu \mathrm{m}$. In six macaques (supplemental Table 1, available at www.jneurosci.org as supplemental material), the peak of the Fourier spectrum for each column pattern ranged between 416 and $655 \mu \mathrm{m}$, with a mean of $531 \pm 80 \mu \mathrm{m}$ (Fig. $6 B$ ). In the human, the columns were significantly wider than in the macaque, by a factor of $1.6(p<0.005$, Wilcoxon's rank-sum test). There tended to be fewer columns in the human, with $100 \pm 21$ column pairs along the V1/V2 border compared with $120 \pm 17$ pairs in the macaque, but this difference did not reach statistical significance $(p=0.191$, Wilcoxon's rank-sum test). To assess the variability of column spacing within individual cortices, we plotted the width versus the peak of the Fourier spectrum for each column pattern from each case (Fig. 6C). The mean ratio was higher in the human $(0.84 \pm 0.06)$ than in the macaque $(0.61 \pm$ $0.04)$. This difference was significant ( $p<$ 0.005 , Wilcoxon's rank-sum test), indicating that Fourier power was distributed over a greater range of column widths in the human patterns. This was consistent with the general impression gleaned from visual inspection of the mosaics: the columns appeared more heterogeneous in spacing and morphology in humans compared with macaques. The width versus peak of the Fourier spectra compiled in both hemispheres of seven normal squirrel monkeys 
Table 1. Measurements made from flat-mounts in human cases

\begin{tabular}{|c|c|c|c|c|c|c|c|c|c|c|c|c|c|c|}
\hline \multirow[b]{2}{*}{ Case \# } & \multirow[b]{2}{*}{ Blind eye } & \multirow[b]{2}{*}{ Hem } & \multicolumn{3}{|c|}{ Surface area } & \multirow{2}{*}{$\begin{array}{l}\text { Single column } \\
\text { width, Fourier } \\
\text { peak }(\mu \mathrm{m})\end{array}$} & \multirow{2}{*}{$\begin{array}{l}\text { \# of } \\
\text { column } \\
\text { pairs on } \\
\text { border }\end{array}$} & \multirow{2}{*}{$\begin{array}{l}\text { Perimeter } \\
\text { of binocular } \\
\text { cortex (mm) }\end{array}$} & \multirow{2}{*}{$\begin{array}{l}\text { Single } \\
\text { column width, } \\
\text { measured at } \\
\text { border }(\mu \mathrm{m})\end{array}$} & \multicolumn{3}{|c|}{$\begin{array}{l}\text { Area of contralateral } \\
\text { columns (\%) }\end{array}$} & \multicolumn{2}{|l|}{ V2 } \\
\hline & & & $\begin{array}{l}\text { Total } \\
\left(\mathrm{mm}^{2}\right)\end{array}$ & $\begin{array}{l}\text { Macula } \\
(\%)\end{array}$ & $\begin{array}{l}\text { Monocular } \\
\text { crescent (\%) }\end{array}$ & & & & & Whole & Macula & Periph & $\begin{array}{l}\text { Area } \\
\left(\mathrm{mm}^{2}\right)\end{array}$ & $\begin{array}{l}\text { Stripe } \\
\lambda(\mathrm{mm})\end{array}$ \\
\hline 1 & $\mathrm{~L}$ & $\mathrm{R}$ & 1986 & 64.0 & 6.5 & 910 & 78 & 164 & 1050 & 55.2 & 48.7 & 63.8 & & \\
\hline \multirow[t]{2}{*}{2} & $\mathrm{~L}$ & $R$ & 2878 & 53.5 & 6.4 & 960 & 95 & 187 & 992 & 55.0 & 51.0 & 60.8 & 3038 & 2.3 \\
\hline & & $\mathrm{L}$ & 2625 & 54.9 & 6.5 & 995 & 89 & 193 & 1089 & 59.3 & 54.4 & 66.0 & & \\
\hline 3 & $\mathrm{~L}$ & $\mathrm{R}$ & 3061 & 45.3 & 3.2 & 730 & 126 & 196 & 779 & 54.7 & 48.2 & 62.3 & 3336 & 2.3 \\
\hline \multirow[t]{2}{*}{4} & $\mathrm{~L}$ & $\mathrm{R}$ & 2183 & 49.6 & 8.6 & 910 & 93 & 179 & 960 & 57.3 & 52.1 & 63.7 & & \\
\hline & & $\mathrm{L}$ & 2096 & 45.4 & 7.5 & 910 & 78 & 167 & 1072 & 53.0 & 46.5 & 59.1 & & \\
\hline \multirow[t]{2}{*}{5} & $\mathrm{R}$ & $\mathrm{R}$ & 3477 & 51.8 & 6.0 & 840 & 116 & 203 & 875 & 56.0 & 47.5 & 66.4 & & \\
\hline & & $\mathrm{L}$ & 2795 & 55.6 & 5.6 & 730 & 122 & 203 & 834 & 56.9 & 49.7 & 65.4 & & \\
\hline 6 & $\mathrm{R}$ & $\mathrm{R}$ & 2786 & 53.7 & 12.7 & & & 172 & & 82.5 & 79.4 & 85.3 & & \\
\hline Mean & & & 2643 & 53.1 & 6.0 & 863 & 100 & 185 & 948 & $55.7^{*}$ & 49.5 & $63.4^{*}$ & 3187 & 2.3 \\
\hline SD & & & 476 & 6.5 & 1.8 & 102 & 21 & 16 & 123 & 1.0 & 1.8 & 1.7 & 211 & 0.0 \\
\hline
\end{tabular}

The bold values were not included in the calculation of mean values because subject 6 had shrunken ocular dominance columns. For comparisons with the macaque, values for the left and right hemispheres were averaged and then treated as a single value for statistical analysis. The macula was defined as $0^{\circ}$ to $15^{\circ} .{ }^{*} p<0.01$, significantly different from $50 \%$ (Wilcoxon's rank-sum test). Hem, Hemisphere; L, left; $R$, right; Periph, periphery.

with ocular dominance columns was also plotted (data from Adams and Horton, 2006a, their Fig. 5). The mean ratio was 1.02 , indicating that power spectra of columns are even broader in squirrel monkeys than in humans $(p<0.005$, Wilcoxon's rank-sum test).

\section{Alignment of CO patches and ocular dominance columns}

In humans, as in macaques, $\mathrm{CO}$ patches are located in the center of ocular dominance columns. This relationship was demonstrated in previous studies by sampling small portions of V1 in which patches and columns were sectioned tangentially (Horton and Hedley-Whyte, 1984; Duffy et al., 2007). In optimal regions, the patches in the supragranular layers form clearly defined rows that alternate in contrast between light and dark. Light and dark rows of patches snap into register with light and dark columns in layer 4C.

The preparation of flat-mounts made it possible to confirm the alignment of columns and patches over the entire extent of $\mathrm{V} 1$ in all five normal subjects. In case 2, for example, each ocular dominance column matched a row of patches in the upper layers (supplemental Fig. 1, available at www.jneurosci.org as supplemental material). However, in case 3, we encountered a local exception to this rule. Figure 7 shows the complete montage of columns from the right hemisphere of this subject. The columns had a typical appearance in most regions, forming interdigitated stripes like those illustrated in Figures 2, 3, and 5. In such areas, the columns and patches had a consistent relationship, with the patches located in the middle of columns. This analysis was confirmed by performing cross-correlations between patch pixels and column borders in various regions throughout the montage (see
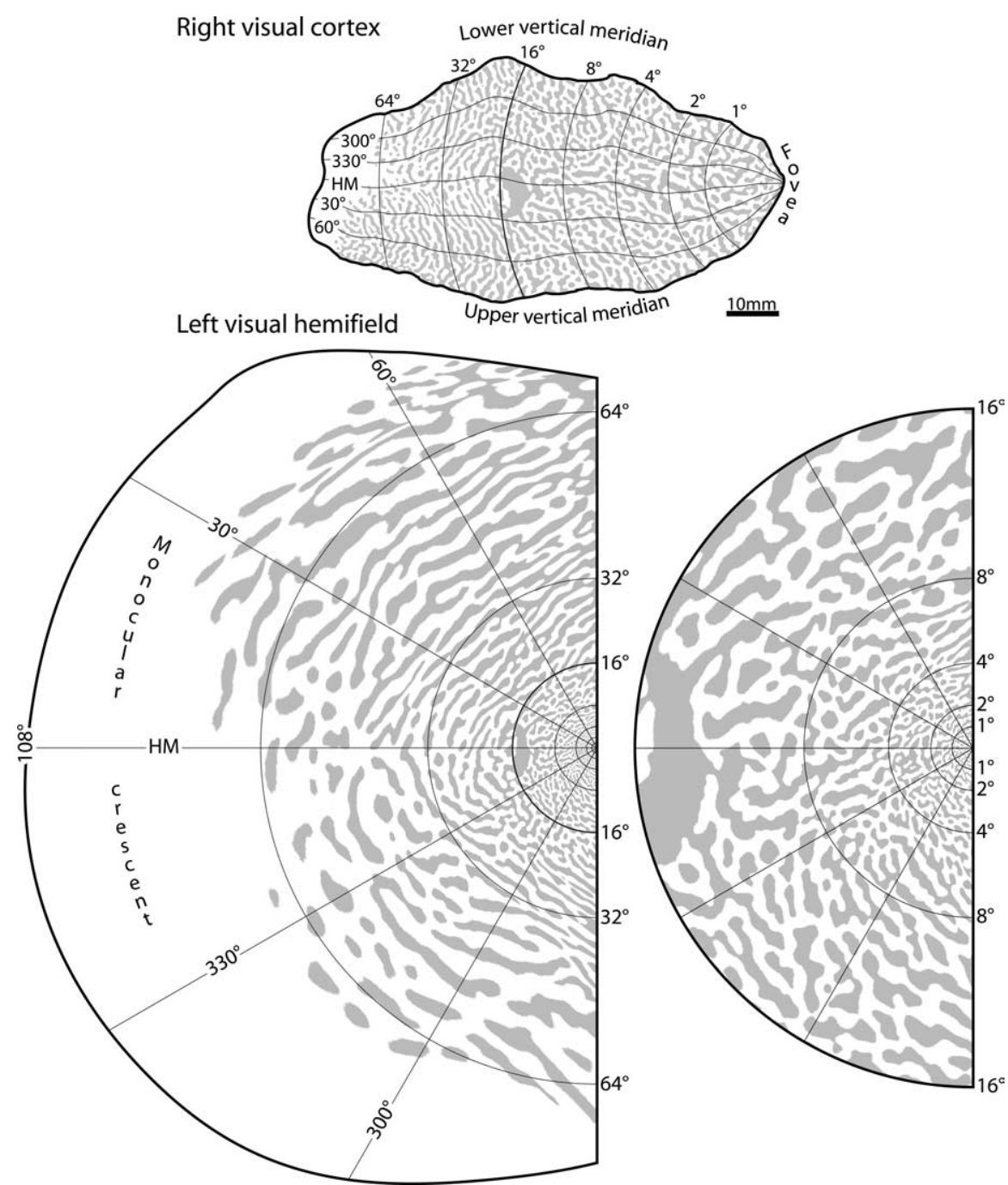

Figure 4. Projection of the ocular dominance columns onto the visual field. The top image shows the retinotopic map superimposed on the pattern of ocular dominance columns in the right visual cortex from case 2 . The isoeccentricity rings are partitioned so that linear cortical magnification along each ring is the same at all polar angles. The bottom image shows the projection of the column pattern onto the visual hemifield. The central $16^{\circ}$ are shown as an inset on the right. The figure shows how the amount of visual field represented by the columns varies with eccentricity. It does not suggest that only part of the visual field is represented by the set of columns for each eye. In fact, the entire binocular visual hemifield is represented twice within layer $4 C$, independently by the set of columns of each eye. HM, Horizontal meridian. 


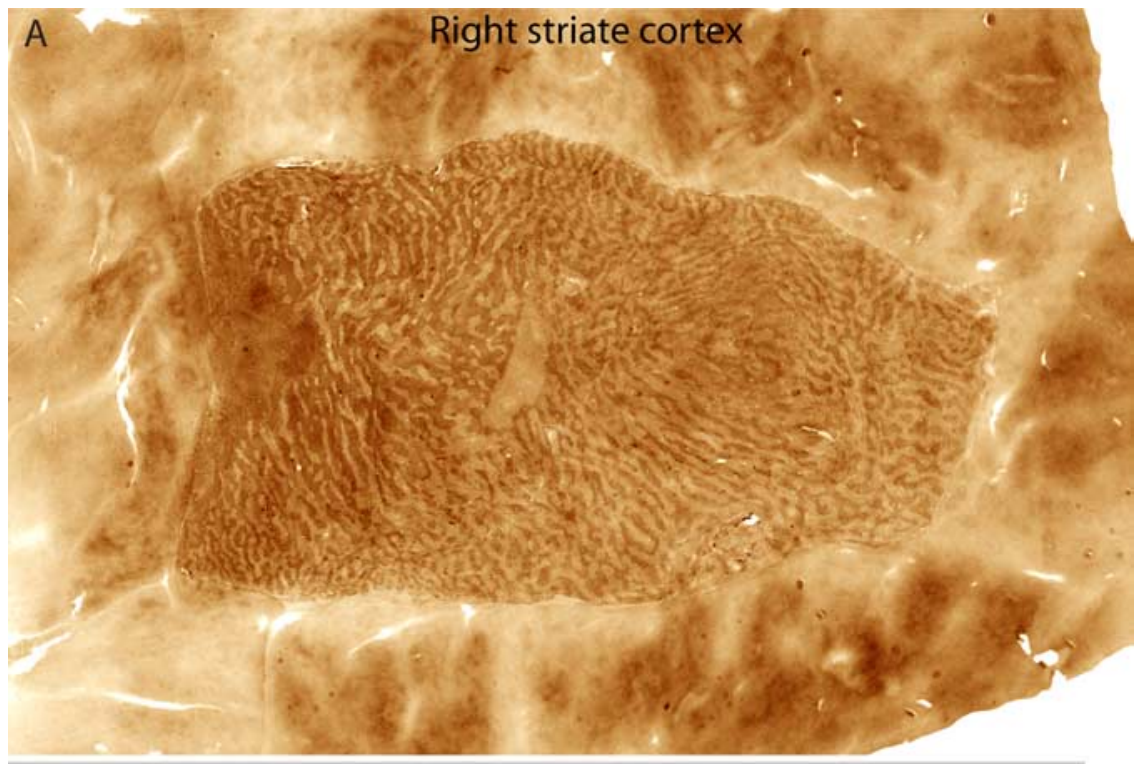

B
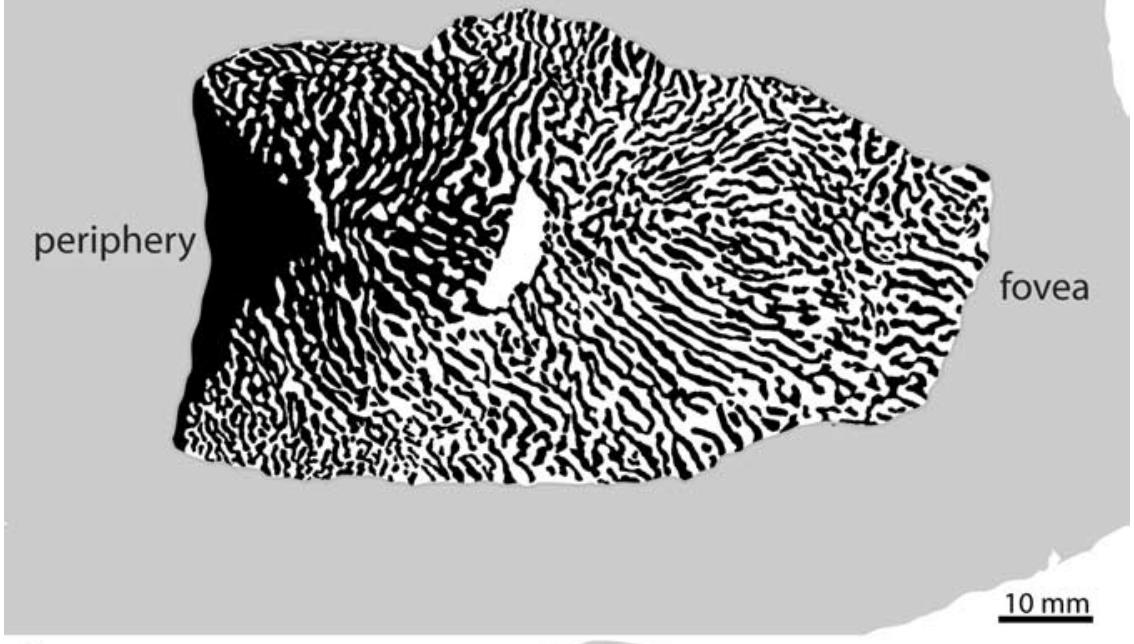

C

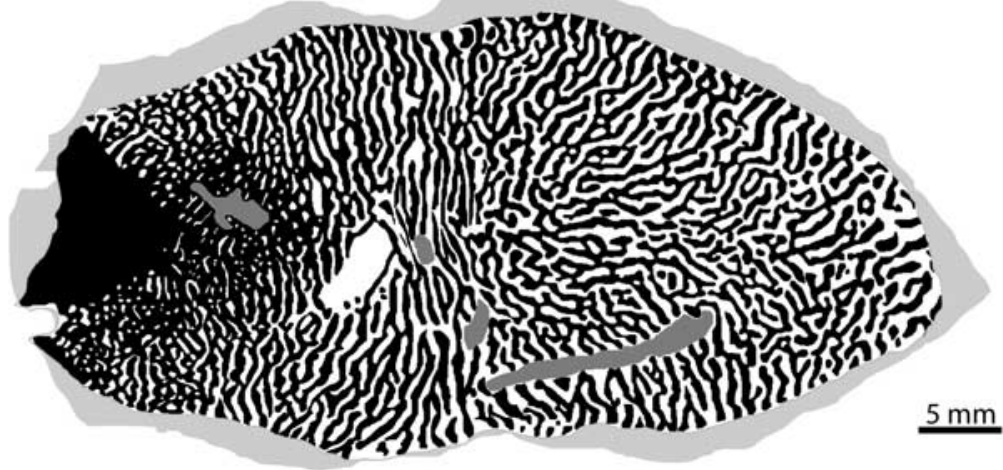

Figure 5. Comparison of ocular dominance columns in the human and macaque. $A$, $C 0$ montage of layer $4 C$ showing ocular dominance columns after loss of the right eye in the right V1 of case 5 . B , Thresholded columns. $\boldsymbol{C}$, Macaque column pattern [Horton and Hocking (1996b), their Fig. 3], magnified to equal the surface area of the human V1 illustrated above. The column patterns in these human and macaque examples are extremely similar, but, in general, columns in humans exhibit greater heterogeneity.

Materials and Methods). Figure 8 shows the spatial average compiled between patches and column borders in a representative area. The bright central zone $\sim 500 \mu \mathrm{m}$ in diameter (Fig. $8 G$ ) signifies that relatively few column borders overlapped pixels located within patches. This result indicates that patches are situated within ocular dominance columns, because they shun column borders. As a control, the spatial correlation was performed after rotating the column pattern by $90^{\circ}$. This generated a low-contrast pattern with no geometric structure (Fig. $8 H$ ). There was a significant difference between the variance of grayscale values of the pixels in the aligned versus rotated spatial correlations $(p<0.001$, Levene's test).

A different result was obtained, however, in a separate region located at the same eccentricity on the other side of the horizontal meridian, near the representation of the lower vertical meridian. In this area, the columns had a very distinctive appearance, forming a fine maze rather than broad stripes. These anomalous columns bore a close resemblance to those identified in some squirrel monkeys (Fig. 7, inset). To confirm this impression, radially summed Fourier spectra were plotted for the human columns and the squirrel monkey columns. They yielded similar power spectra, peaking at a column width of $\sim 450 \mu \mathrm{m}$. Because columns and patches are not aligned in the squirrel monkey, we singled out this region for analysis. A spatial cross-correlation yielded a flat image, demonstrating no evidence of alignment between patches and columns (Fig. 9G). As a control, the crosscorrelation was repeated after rotating the column pattern by $90^{\circ}$ (Fig. $9 H$ ). There was no significant difference in variance between the aligned and rotated spatial averages ( $p>0.05$, Levene's test). From this comparison, we conclude that, when human columns lose their regular, stripe-like morphology, their correlation with $\mathrm{CO}$ patches can be lost.

Cortical representation of the macula Within the representation of the central $15^{\circ}$, the columns serving each eye occupied an equal amount of cortex. However, from $15^{\circ}$ to the border of the monocular crescent, the columns of the contralateral eye became progressively larger, an effect also seen in the macaque (LeVay et al., 1985; Horton and Hocking, 1996b). In this peripheral binocular region of cortex, the columns of the contralateral eye occupied $63 \%$ of layer $4 \mathrm{C}$ ( $\mathrm{Ta}$ ble 1).

In every case, the representation of the blind spot of the contralateral eye could be discerned easily as an oval region in the middle of the cortex devoid of ocular dominance columns. It provided a reliable retinotopic data point: the intersection of the horizontal meridian and the $15^{\circ}$ eccentricity contour. The $15^{\circ}$ eccentricity contour was extended from the blind spot representation to the vertical meridian by assuming equal cortical magnification for all polar angles (Van 
Essen et al., 1984). It was used to divide striate cortex into central and peripheral portions. A mean of $53.1 \pm 6.5 \%$ of striate cortex was devoted to the representation of the central $15^{\circ}$ (Table 1 ). The remaining cortex contained a representation of the peripheral visual field, including the monocular crescent. The monocular crescent, which also lacks ocular dominance columns, filled a mean of $6.0 \pm 1.8 \%$ of the cortex. This figure was close to the value of $5 \%$ reported in the macaque (Horton and Hocking, 1996b).

In the macaque, as in the human, the blind spot is centered at $15^{\circ}$ eccentricity (Harwerth et al., 1993; Sasaoka et al., 2005). It was used to divide the macaque column mosaics into central and peripheral fractions, following the same procedure used for the human cases (this procedure is illustrated in supplemental Table 1, available at www.jneurosci.org as supplemental material). In the macaque, the central $15^{\circ}$ filled $60.9 \pm 2.8 \%$ of striate cortex. Thus, a slightly greater proportion of striate cortex was devoted to central vision in the macaque than in the human ( 60.9 vs $53.1 \%$; $p<0.05$, Wilcoxon's rank-sum test).

\section{Shrinkage of ocular dominance columns from early deprivation}

In a single case, it was possible to analyze the effect of early visual loss on the morphology of ocular dominance columns. Case 6 was a 94-year-old man who suffered an injury to his right eye at age 4 months, resulting in opacity of the cornea and partial loss of sight. An examination two decades later showed a retinal detachment and loss of all light perception in the eye.

Only glimpses of columns were present in the left hemisphere. In the right hemisphere, their pattern could be reconstructed more completely. The pale columns serving the right eye were shrunken compared with the dark columns belonging to the left eye (Fig. 10), presumably because the injury to the right eye occurred at such a young age. In portions of the mosaic in which columns were present, those belonging to the right eye occupied $18 \%$ of the cortical surface area.

\section{Cytochrome oxidase stripes in human V2}

In V2, the CO stain showed a pattern of alternating dark and light stripes oriented perpendicular to the borders shared with V1 and V3. The stripes stopped at the border shared with V3 and therefore served as a useful marker to identify the outer boundary of V2. In cases 2 and 3, the surface area of the right V1 and V2 could be measured reliably. For case 2, V1 equaled $2878 \mathrm{~mm}^{2}$ and V2 equaled $3038 \mathrm{~mm}^{2}$. For case 3, V1 equaled $3061 \mathrm{~mm}^{2}$ and V2 equaled $3336 \mathrm{~mm}^{2}$. These data imply that $\mathrm{V} 2$ is $\sim 10 \%$ greater in surface area than $\mathrm{V} 1$ in the human. In the macaque, in contrast, V2 is 25\% smaller than V1 (Sincich et al., 2003).

In many primates, there are two classes of dark stripes: thick and thin (Tootell et al., 1983). However, it was not possible to recognize thick and thin stripes in any of the human cases we examined. In regions in which the V2 stripes were seen most clearly, each set (dark plus light) had a mean width of $2.3 \mathrm{~mm}$ (Figs. 3B, 7B). individual mosaics.
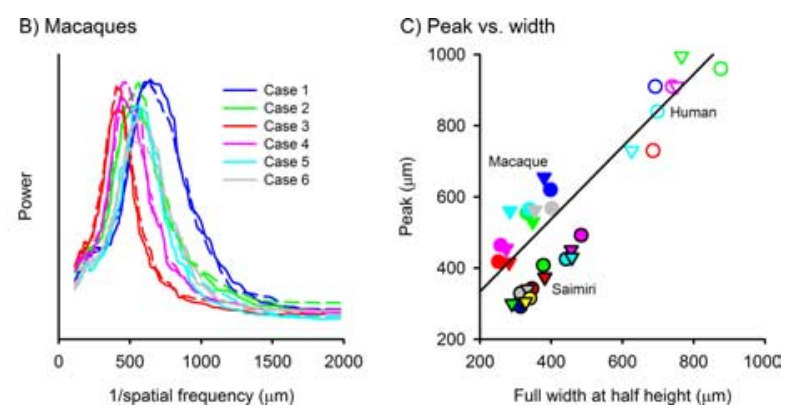

Figure 6. Comparison of column widths in human and macaque. $\boldsymbol{A}$, Radially summed, two-dimensional Fourier spectra showing the relative power at different spatial scales for each of the nine human cortices. The black trace denotes the macaque V1 shown in Figure 5C, scaled to the surface area of case 5, whose power spectrum it matches closely. Solid traces, Right V1; dashed (rigest). Each width was measured at half-height from a best-fit Gaussian function. The solid patterns. However, the squirrel monkeys had the highest mean ratio (1.02), indicating the most diverse column spacing within

\section{Discussion}

Functional magnetic resonance imaging (fMRI) has become the dominant approach for using metabolic changes induced by sensory stimulation to probe patterns of cellular organization in the human cerebral cortex. Unfortunately, columnar structures in the cortex below $1 \mathrm{~mm}$ in size are difficult to map with fMRI, because of limits in the spatial resolution of the technique (Zhao et al., 2005; Moon et al., 2007; Shmuel et al., 2007). Several fMRI studies have demonstrated the existence of ocular dominance columns in human striate cortex (Menon et al., 1997; Dechent and Frahm, 2000; Cheng et al., 2001; Goodyear and Menon, 2001). However, it has not been possible to reconstruct ocular dominance columns over a wide area or to compare their structure meaningfully among different subjects. Here, we recovered patterns of metabolic activity present during life by mapping the cellular distribution of a mitochondrial enzyme after death. The entire medial face of the occipital lobe was flattened for analysis, an area corresponding to $\sim 10 \%$ of the cortical surface in a human brain hemisphere. The complete pattern of ocular dominance columns could be reconstructed by imaging CO levels at submillimeter resolution in six individuals with a history of monocular visual loss.

Conflicting values have been reported for the mean surface area of human striate cortex, from 3450 to $2070 \mathrm{~mm}^{2}$ (Brodmann, 1918; Putnam, 1926; Popoff, 1927; Filimonoff, 1932). This wide range reflects, in part, different methods used to process and measure the cortex. However, there is ample evidence to suggest that the variability in V1 area is real (Amunts et al., 2007). In the largest study, 52 hemispheres were fixed in $10 \%$ formaldehyde and sectioned coronally every $2-3 \mathrm{~mm}$ (Stensaas et al., 1974). The specimens ranged between 1284 and $3702 \mathrm{~mm}^{2}$, with a mean of $2134 \mathrm{~mm}^{2}$. This average value is low, reflecting the use of heavily fixed tissue and perhaps a systematic error in approximating surface area from serial two-dimensional strips. We examined nine hemispheres, which were lightly fixed, and found a range of $1986-3477 \mathrm{~mm}^{2}$, with a mean of $2643 \mathrm{~mm}^{2}$.

Our data showed that human V1 has approximately twice the surface area of macaque V1 (Table 1 and supplemental Table 1, available at www.jneurosci.org as supplemental material). In both species, the size of V1 varies by twofold among normal 


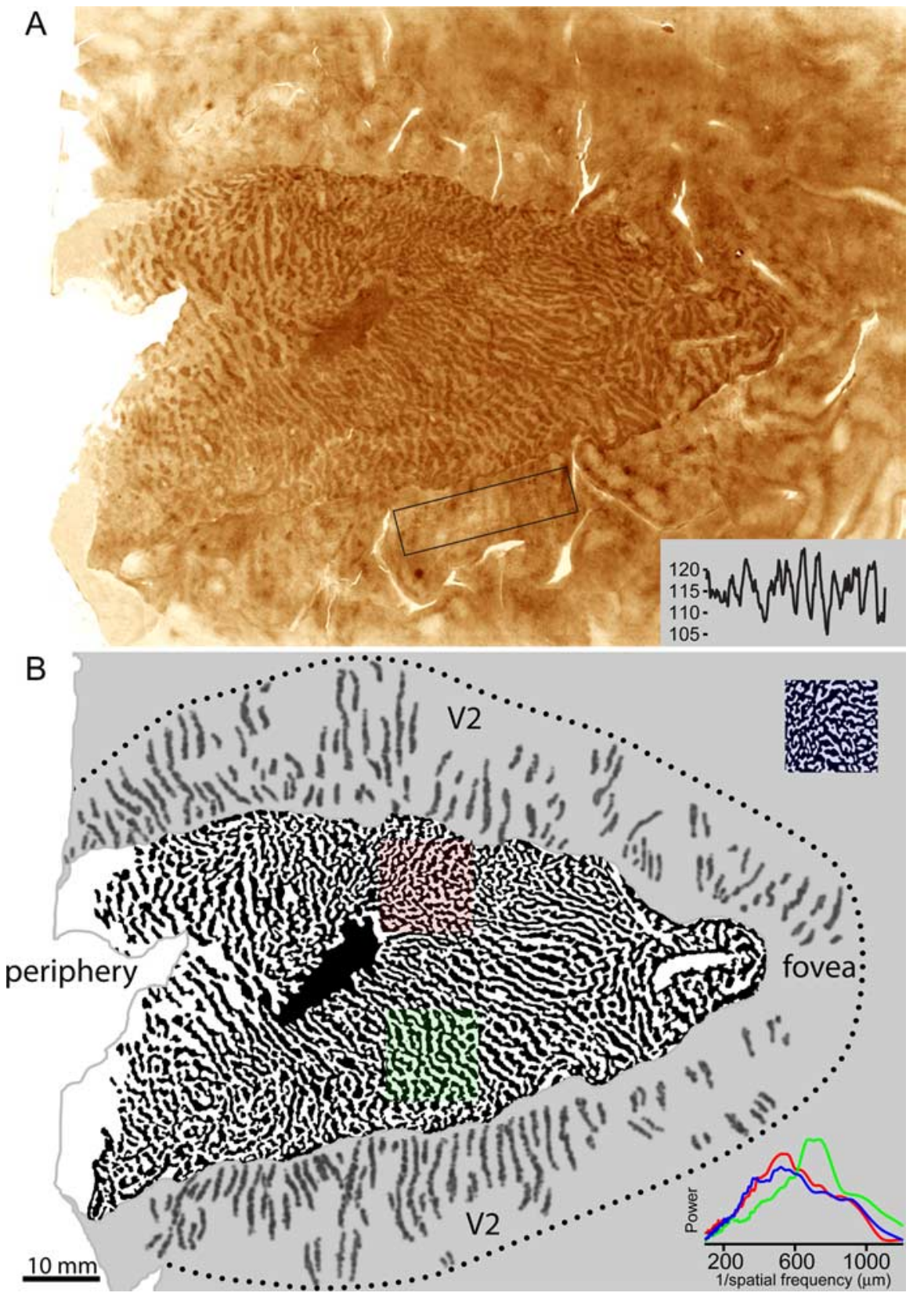

Figure 7. Variation in column periodicity and morphology within human V1. A, CO montage of layer 4C of the right striate cortex in case 3, showing ocular dominance columns rendered visible by loss of the left eye. The C 0 stripes in V2 enclosed by the rectangle were analyzed with a densitometer (inset, bottom right). Their optical density fluctuated with a mean periodicity of 2.3 $\mathrm{mm}$. $\boldsymbol{B}$, Fourier-filtered, thresholded image of the ocular dominance columns. The green and red shaded zones represent mirror image locations across the horizontal meridian, centered at an eccentricity of $\sim 10^{\circ}$. They are analyzed further in Figures 8 and 9 , respectively. The green zone contains typical human columns, whereas the red zone highlights columns that are unusually fine and labyrinthine, resembling those sometimes found in squirrel monkeys. The blue-coded column mosaic (top right corner) is an example of ocular dominance columns from a squirrel monkey, at the same scale [Adams and Horton (2003), their Fig. 3]. The Fourier plots (bottom right corner) are similar for the squirrel monkey columns and the human columns located in the red-shaded zone. In contrast, the human columns in the green-shaded zone have a higher mean periodicity. The dotted line indicates V2/V3 border.

subjects (Van Essen et al., 1984; Dougherty et al., 2003). The biggest macaque $\mathrm{V} 1$ we examined $\left(1646 \mathrm{~mm}^{2}\right)$ almost equaled the smallest human V1 $\left(1986 \mathrm{~mm}^{2}\right)$. A larger V1 correlates with a larger LGN and optic tract, but the functional significance of size variation is unknown (Andrews et al., 1997). Duncan and Boynton (2003) found that human subjects with a larger V1 have better Vernier acuity. However, they found no correlation be- tween V1 area and grating resolution. We tested all but one subject before death (Snellen acuity, computerized perimetry), and none showed a conspicuous difference in visual function that might correlate with V1 surface area.

Ocular dominance columns have never been reported to be absent in the macaque, but they are lacking in approximately half (8 of 16) of normal squirrel monkeys (Adams and Horton, 2006a). To learn whether ocular dominance columns are universal in humans, we examined as many cases as possible. With the six cases described here, a total of 12 subjects ( 11 white, 1 black) has been reported in the literature (Horton and Hedley-Whyte, 1984; Horton et al., 1990; Horton and Stryker, 1993; Duffy et al., 2007). Ocular dominance columns have been found in every individual. However, they exhibit remarkable variability in morphology and spacing, presumably because of genetic factors (Kaschube et al., 2002). Analysis of Fourier spectra showed that human columns were more variable than those in macaques but less variable than those in squirrel monkeys (Fig. 6C). On average, ocular dominance columns were 1.7 times wider in the human compared with the macaque, but, because human V1 surface area is larger, there was no overall difference in the number of column sets. Thus, the ocular dominance columns are scaled proportionately to V1 size in the two species. In both species, the ipsilateral eye and the contralateral eye occupied equal territory within the central $15^{\circ}$. Beyond the blind spot, the columns of the contralateral eye filled more of the cortical surface area. This peripheral bias correlated with the greater density of ganglion cells in nasal retina, compared with temporal retina, at eccentricities beyond $15^{\circ}$ (Curcio and Allen, 1990).

The macaque is used widely in experimental studies to draw inferences about the human visual system. In case 5 , the pattern formed by the columns was extremely similar, except for the difference in scale, to the pattern reconstructed previously in a macaque using similar methods (Fig. 5, compare $B, C)$. However, as emphasized above, usually human columns form a more irregular array with greater local heterogeneity in spacing than macaque columns. In the human (Fig. 8) (supplemental Fig. 1, available at www.jneurosci.org as supplemental material), as in the macaque, CO patches are located in the middle of ocular dominance columns. However, in one subject, the columns lost their stripe-like configuration within part of the mosaic and resembled the columns present in some squirrel monkeys (Fig. 7). In the squirrel monkey, there is no spatial relationship between patches and ocular dominance columns (Hor- 

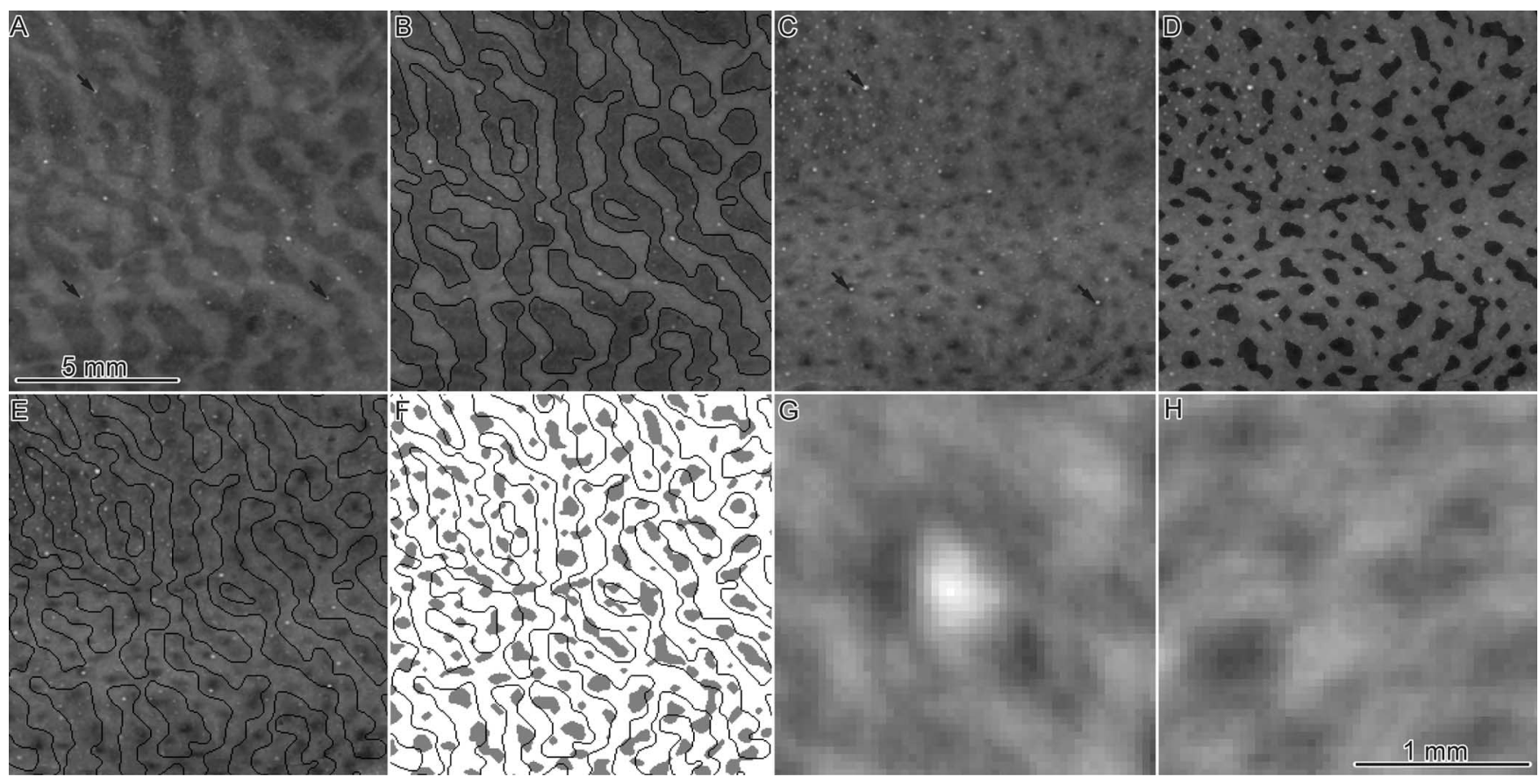

Figure 8. Alignment of $\mathrm{CO}$ patches and columns in the human. $\boldsymbol{A}$, Montage of ocular dominance columns in layer $4 \mathrm{C}$ from the green-shaded zone in Figure 7. $\boldsymbol{B}$, Borders of ocular dominance columns in $\boldsymbol{A}$, defined by the Canny edge detector algorithm, drawn one pixel wide. $\boldsymbol{C}, C 0$ patches in layer 3 from the same region. Arrows show examples of blood vessels used to align $\boldsymbol{A}$ and $\boldsymbol{C}$. $\boldsymbol{D}$, Thresholded patches, superimposed on the image in $\boldsymbol{C}$. $\boldsymbol{E}$, Column borders in $\boldsymbol{B}$ transferred onto the image in $\boldsymbol{C}$, showing the alignment between patches and ocular dominance columns. $\boldsymbol{F}$, Thresholded patches in $\boldsymbol{D}$ with ocular dominance column borders. $\mathbf{G}$, Spatial cross-correlation of patches and column borders. The plot shows the mean density of pixels comprising column borders plotted with respect to every patch pixel (as defined in $\boldsymbol{D}$ ), with each patch pixel centered in the image. The white center of the spatial average indicates that column borders rarely pass through patches. $\boldsymbol{H}$, Spatial average as in $\boldsymbol{G}$, generated after rotating the column border image $90^{\circ}$. The rotation eliminates the structure seen in $\boldsymbol{G}$ by randomizing the relationship between column borders and patches (see Materials and Methods). Scale bars: $\boldsymbol{A}-\boldsymbol{F}, 5 \mathrm{~mm} ; \boldsymbol{G}, \boldsymbol{H}, 1 \mathrm{~mm}$.
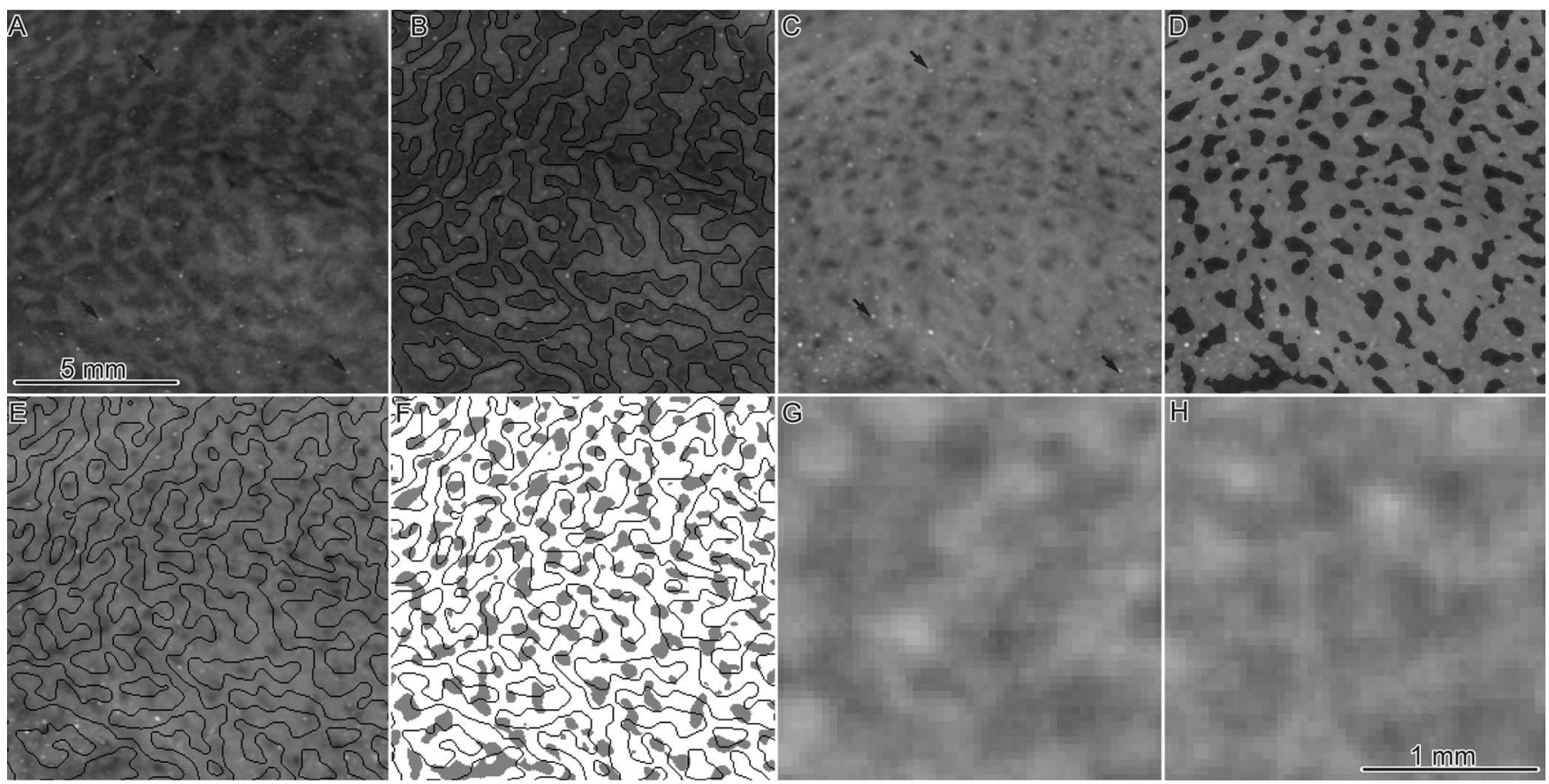

Figure 9. A cortical zone without patch/column alignment. $A$, Montaged ocular dominance columns from the red-shaded area in Figure 7 , in which they form an unusually intricate, irregular pattern. $\boldsymbol{B}$, Borders of ocular dominance columns in $\boldsymbol{A}$, one pixel wide. $\boldsymbol{C}, \mathbf{C} 0$ patches in layer 3 from the same region. Arrows show blood vessels used for alignment. $D$, Binary map of the $C 0$ patches, superimposed on the image in $\boldsymbol{C}$. $\boldsymbol{E}$, Borders of columns in $\boldsymbol{B}$ superimposed on the patches in $\boldsymbol{C}$. $\boldsymbol{F}$, Overlay of thresholded patches and column borders, showing no clear relationship. $\boldsymbol{G}$, Spatial cross-correlation of patches and column borders. The plot shows the mean density of pixels comprising column borders plotted with respect to every patch pixel (as defined in $D$ ), with each patch pixel centered in the image. The low contrast of the image indicates that there is no systematic relationship between column borders and patch pixels. $\boldsymbol{H}$, Spatial average as in $\boldsymbol{G}$, generated after rotating the column borders $90^{\circ}$ with respect to the patches. The spatial averages in $\mathbf{G}$ and $\boldsymbol{H}$ appear similar and have no significant difference in grayscale variance. This means that the patches fit no better in register with aligned columns than rotated columns. 


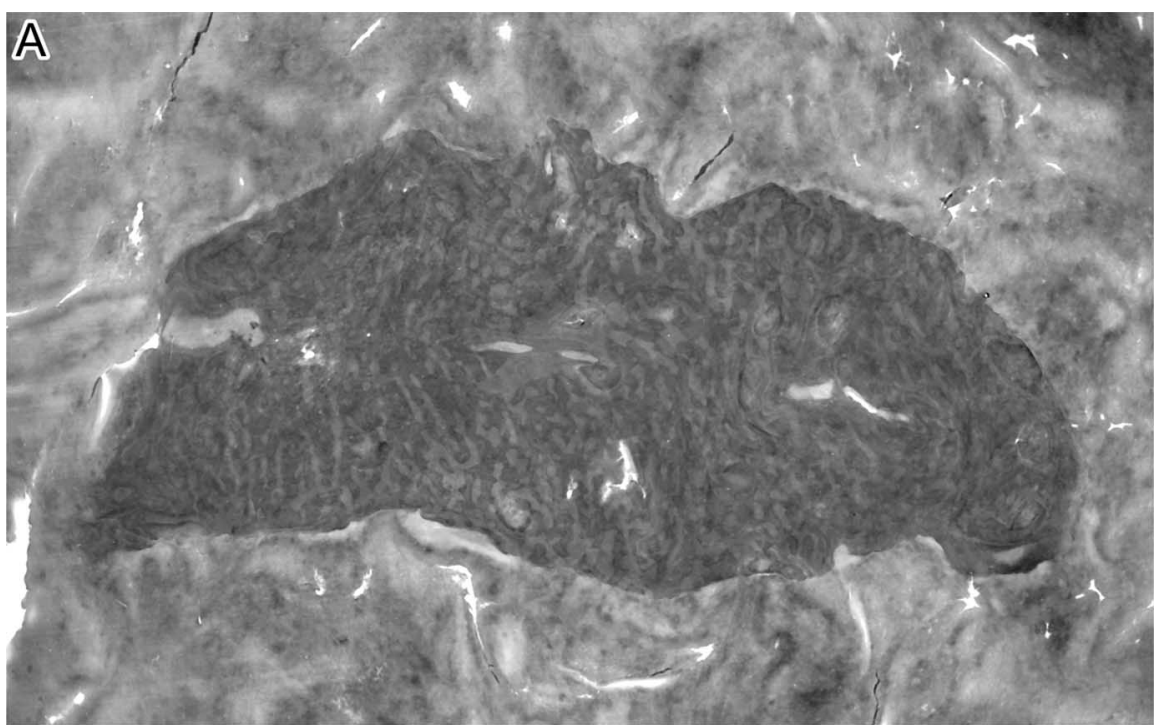

B

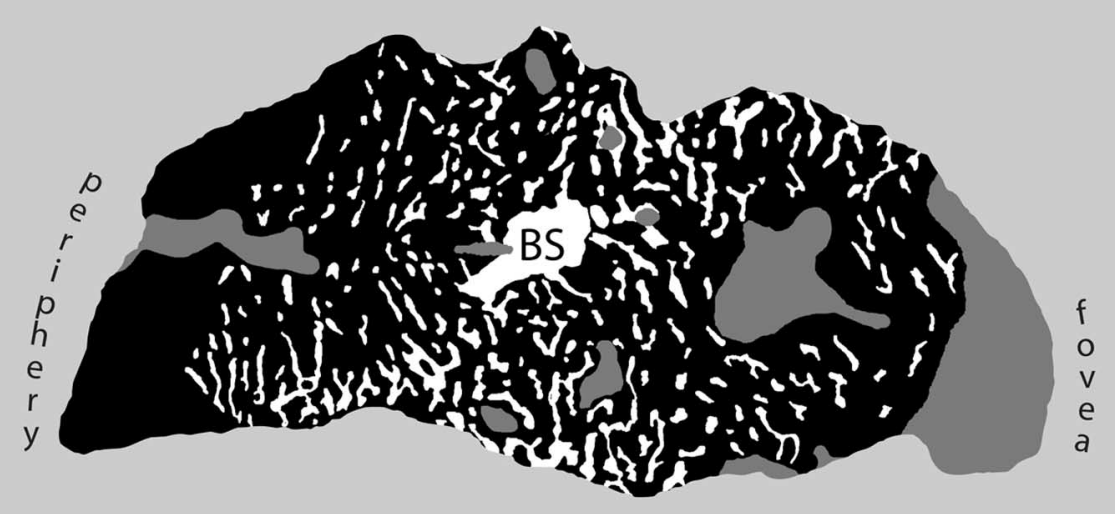

Figure 10. Shrinkage of ocular dominance columns caused by visual deprivation during the critical period. $\boldsymbol{A}, \mathrm{C} 0$ montage of layer $4 \mathrm{C}$ of the right $\mathrm{V} 1$ from case 6 . The subject lost vision in his right eye at age 4 months attributable to a corneal injury. The pale ocular dominance columns belonging to the right eye appear shrunken compared with the dark regions of cortex serving the intact left eye. $\boldsymbol{B}$, Manual drawing of the ocular dominance columns. Regions where the columns could not be drawn reliably are shaded gray. BS, Blind spot.

ton and Hocking, 1996a; Adams and Horton, 2006b). In the portion of the human mosaic in which the columns looked like squirrel monkey columns, there was no spatial correlation between patches and columns (Fig. 9). This finding implies that alignment between columns and patches depends on the morphology of the columns, not the identity of the species. When columns assume a less banded appearance, they appear to have little or no spatial correlation with patches. A lack of correlation between patches and columns has also been shown in the cat and galago (Dyck and Cynader, 1993; Xu et al., 2005), species that share with squirrel monkeys blob-like rather than stripe-like ocular dominance columns [although a weak correlation may in fact be present in cat (Murphy et al., 1995)].

The percentage of human striate cortex allocated to the representation of the macula is controversial (Inouye, 1909; Holmes and Lister, 1916; Horton and Hoyt, 1991; McFadzean et al., 1994; Korogi et al., 1997; Wong and Sharpe, 1999). All mapping studies that rely on structural imaging share a common problem: the
$10 \mathrm{~mm}$

substantial degree of variation that occurs in the size and location of striate cortex (Amunts et al., 2007). Although the stria of Gennari can be detected using a highresolution protocol (Clark et al., 1992), it is not visible on magnetic resonance images obtained for routine clinical purposes. Thus, uncertainty regarding the precise extent of striate cortex has confounded efforts to develop maps based on the correlation of visual field defects with the location of occipital lesions.

Reconstruction of the ocular dominance columns provides a vital retinotopic landmark: the location of the blind spot representation. We plotted the $15^{\circ}$ eccentricity contour through the middle of the blind spot for each column montage. A mean of $53.1 \%$ of striate cortex was devoted to the representation of the central $15^{\circ}$ (Table 1). This percentage was significantly less than the $60.9 \%$ of striate cortex devoted to central vision in the macaque. This result must be tendered with caution, because the path followed by the $15^{\circ} \mathrm{ec}-$ centricity contour from the middle of the blind spot to the vertical meridian in both species was extrapolated by assuming that cortical magnification factor is equal for all polar angles. However, there is unlikely to be much difference in the layout of the eccentricity contours in humans and macaques, because V1 has a similar elliptical shape in the two species, with an aspect ratio of $\sim 2: 1$ (Horton and Hocking, 1996b).

With fMRI, it has been reported that a greater proportion of striate cortex is devoted to macular vision in the human than in the macaque (Sereno et al., 1995). In this study, the central $10-13^{\circ}$ of visual field was stimulated in human subjects to derive a value for cortical magnification factor. For comparison with the macaque, cortical magnification factor was scaled to compensate for the difference in V1 area between the two species. The investigators found that, in the human, compared with the macaque, 35\% more tissue was allocated to the representation of the central $12^{\circ}$. As mentioned previously, there is a twofold variation in the size of $\mathrm{V} 1$ among individual members of each species, which means that cortical magnification factor also varies by twofold. To get around this problem, a superior approach is to calculate for each subject the percentage of $\mathrm{V} 1$ devoted to the central portion of the visual field. Unfortunately, in the study by Sereno et al. (1995), visual stimulation was confined to the central 10$13^{\circ}$, giving investigators no information about total V1 area in each subject. This made it impossible to calculate directly the percentage of V1 serving the central $10-13^{\circ}$. Subsequent fMRI studies have not reported a relatively greater representation of the macula in the human (DeYoe et al., 1996; Engel et al., 1997; Dougherty et al., 2003). Clearly, additional efforts to define the human retinotopic map in V1 by stimulating all portions of the entire visual field are warranted. Although one might expect the 
macula to occupy the same proportion of V1 in humans and macaques, our data indicate that a small difference exists.

Monocular eyelid suture in early life causes shrinkage of the columns of the deprived eye and expansion of the columns of the open eye (Hubel et al., 1977). This phenomenon demonstrates vividly how sensory experience can affect the columnar architecture of the brain, but it has not been demonstrated previously in humans. In case 6 , an eye injury at age 4 months caused a corneal opacity, tantamount to eyelid suture or congenital cataract. The columns of the deprived eye shrank to occupy only $18 \%$ of the cortex. Presumably the injury occurred during the critical period for column plasticity. Previously, it was shown that enucleation at age 1 week in the human causes obliteration of the columns of the missing eye (Horton and Hocking, 1998). The less drastic effect of visual loss at age 4 months presumably reflects a decline in susceptibility to column shrinkage near the end of the critical period. The most remarkable feature of this case is that the columns of the deprived eye survived, albeit shrunken, even after $>90$ years of blindness.

In cases 2 and 3, the V2/V3 border was clear enough to recognize the outer boundary of area V2. In both cases, V2 was slightly larger than V1. Surprisingly, the CO stain revealed only one class of dark stripe in V2. Failure to identify thick and thin stripes was not attributable to the loss of vision in one eye, because both types of dark stripe are easily detectable after monocular enucleation in the macaque (Horton and Hocking, 1998). In macaques, thin stripes project to V4, whereas thick stripes supply the middle temporal area MT (DeYoe and Van Essen, 1985; Shipp and Zeki, 1985). Our results raise the intriguing possibility that, in the human, the output from V2 to higher visual areas may not be segregated by two different classes of CO dark stripe.

The use of CO histochemistry in large, flattened sections of the human occipital lobe has been fruitful, allowing one to map basic features of the visual cortex such as patches, ocular dominance columns, and V2 stripes. These findings encourage one to apply similar methods to probe the functional architecture of other areas within the human cerebral cortex. It may also be valuable to combine fMRI imaging with CO histochemistry, in altruistic subjects who are willing to donate their tissues for laboratory study after death.

\section{References}

Adams DL, Horton JC (2003) Capricious expression of cortical columns in the primate brain. Nat Neurosci 6:113-114.

Adams DL, Horton JC (2006a) Ocular dominance columns in strabismus. Vis Neurosci 23:795-805.

Adams DL, Horton JC (2006b) Monocular cells without ocular dominance columns. J Neurophysiol 96:2253-2264.

Amunts K, Armstrong E, Malikovic A, Homke L, Mohlberg H, Schleicher A, Zilles K (2007) Gender-specific left-right asymmetries in human visual cortex. J Neurosci 27:1356-1364.

Anderson PA, Olavarria J, Van Sluyters RC (1988) The overall pattern of ocular dominance bands in cat visual cortex. J Neurosci 8:2183-2200.

Andrews TJ, Halpern SD, Purves D (1997) Correlated size variations in human visual cortex, lateral geniculate nucleus, and optic tract. J Neurosci 17:2859-2868.

Blasdel G, Campbell D (2001) Functional retinotopy of monkey visual cortex. J Neurosci 21:8286-8301.

Boyd JD, Casagrande VA (1999) Relationships between cytochrome oxidase (CO) blobs in primate primary visual cortex (V1) and the distribution of neurons projecting to the middle temporal area (MT). J Comp Neurol 409:573-591.

Brodmann K (1918) Individuelle Variationen der Sehsphäre und ihr Bedeutung für die Klinik der Hinterhauptschüsse. Allgz Psychiat (Berlin) 74:564-568.
Canny J (1986) A computational approach to edge detection. IEEE Trans Pattern Anal Mach Intell 8:679-698.

Cheng K, Waggoner RA, Tanaka K (2001) Human ocular dominance columns as revealed by high-field functional magnetic resonance imaging. Neuron 32:359-374.

Clark VP, Courchesne E, Grafe M (1992) In vivo myeloarchitectonic analysis of human striate and extrastriate cortex using magnetic resonance imaging. Cereb Cortex 2:417-424.

Curcio CA, Allen KA (1990) Topography of ganglion cells in human retina. J Comp Neurol 300:5-25.

Dechent P, Frahm J (2000) Direct mapping of ocular dominance columns in human primary visual cortex. NeuroReport 11:3247-3249.

DeYoe EA, Van Essen DC (1985) Segregation of efferent connections and receptive field properties in visual area V2 of the macaque. Nature 317:58-61.

DeYoe EA, Carman GJ, Bandettini P, Glickman S, Wieser J, Cox R, Miller D, Neitz J (1996) Mapping striate and extrastriate visual areas in human cerebral cortex. Proc Natl Acad Sci USA 93:2382-2386.

Dougherty RF, Koch VM, Brewer AA, Fischer B, Modersitzki J, Wandell BA (2003) Visual field representations and locations of visual areas V1/2/3 in human visual cortex. J Vis 3:586-598.

Duffy KR, Murphy KM, Frosch MP, Livingstone MS (2007) Cytochrome oxidase and neurofilament reactivity in monocularly deprived human primary visual cortex. Cereb Cortex 17:1283-1291.

Duncan RO, Boynton GM (2003) Cortical magnification within human primary visual cortex correlates with acuity thresholds. Neuron 38:659-671.

Dyck RH, Cynader MS (1993) An interdigitated columnar mosaic of cytochrome oxidase, zinc, and neurotransmitter-related molecules in cat and monkey visual cortex. Proc Natl Acad Sci USA 90:9066-9069.

Engel SA, Glover GH, Wandell BA (1997) Retinotopic organization in human visual cortex and the spatial precision of functional MRI. Cereb Cortex 7:181-192.

Filimonoff I (1932) Über die Variabilität der Grosshirnrindenstruktur. Regio occipitalis beim erwachsenen Menschen. J Psychol Neurol 44:1-96.

Florence SL, Kaas JH (1992) Ocular dominance columns in area 17 of Old World macaque and talapoin monkeys: complete reconstructions and quantitative analyses. Vis Neurosci 8:449-462.

Goodyear BG, Menon RS (2001) Brief visual stimulation allows mapping of ocular dominance in visual cortex using fMRI. Hum Brain Mapp 14:210-217.

Harwerth RS, Smith III EL, DeSantis L (1993) Behavioral perimetry in monkeys. Invest Ophthalmol Vis Sci 34:31-40.

Hitchcock PF, Hickey TL (1980) Ocular dominance columns: evidence for their presence in humans. Brain Res 182:176-179.

Holmes G, Lister WT (1916) Disturbances of vision from cerebral lesions, with special reference to the cortical representation of the macula. Brain 39:34-70.

Horton JC (1984) Cytochrome oxidase patches: a new cytoarchitectonic feature of monkey visual cortex. Philos Trans R Soc Lond B Biol Sci 304:199-253.

Horton JC, Hedley-Whyte ET (1984) Mapping of cytochrome oxidase patches and ocular dominance columns in human visual cortex. Philos Trans R Soc Lond B Biol Sci 304:255-272.

Horton JC, Hocking DR (1996a) Anatomical demonstration of ocular dominance columns in striate cortex of the squirrel monkey. J Neurosci 16:5510-5522.

Horton JC, Hocking DR (1996b) Intrinsic variability of ocular dominance column periodicity in normal macaque monkeys. J Neurosci 16:7228-7239.

Horton JC, Hocking DR (1998) Effect of early monocular enucleation upon ocular dominance columns and cytochrome oxidase activity in monkey and human visual cortex. Vis Neurosci 15:289-303.

Horton JC, Hoyt WF (1991) The representation of the visual field in human striate cortex: a revision of the classic Holmes map. Arch Ophthalmol 109:816-824.

Horton JC, Stryker MP (1993) Amblyopia induced by anisometropia without shrinkage of ocular dominance columns in human striate cortex. Proc Natl Acad Sci USA 90:5494-5498.

Horton JC, Dagi LR, McCrane EP, de Monasterio FM (1990) Arrangement of ocular dominance columns in human visual cortex. Arch Ophthalmol 108:1025-1031. 
Hubel DH, Freeman DC (1977) Projection into the visual field of ocular dominance columns in macaque monkey. Brain Res 122:336-343.

Hubel DH, Wiesel TN (1969) Anatomical demonstration of columns in the monkey striate cortex. Nature 221:747-750.

Hubel DH, Wiesel TN (1977) The Ferrier Lecture: functional architecture of macaque monkey visual cortex. Proc R Soc Lond B Biol Sci 198:1-59.

Hubel DH, Wiesel TN, LeVay S (1977) Plasticity of ocular dominance columns in monkey striate cortex. Philos Trans R Soc Lond B Biol Sci 278:377-409.

Hübener M, Shoham D, Grinvald A, Bonhoeffer T (1997) Spatial relationships among three columnar systems in cat area 17. J Neurosci 17:9270-9284.

Inouye T (1909) Die Sehstörungen bei Schussverletzungen der kortikalen Sehsphäre nach Beobachtungen an Verwundeten der letzten japanischen Kriege. Leipzig, Germany: Engelmann.

Kaschube M, Wolf F, Geisel T, Löwel S (2002) Genetic influence on quantitative features of neocortical architecture. J Neurosci 22:7206-7217.

Korogi Y, Takahashi M, Hirai T, Ikushima I, Kitajima M, Sugahara T, Shigematsu Y, Okajima T, Mukuno K (1997) Representation of the visual field in the striate cortex: comparison of MR findings with visual field deficits in organic mercury poisoning (Minamata disease). AJNR Am J Neuroradiol 18:1127-1130.

LeVay S, Connolly M, Houde J, Van Essen DC (1985) The complete pattern of ocular dominance stripes in the striate cortex and visual field of the macaque monkey. J Neurosci 5:486-501.

Lia B, Olavarria JF (1996) The distribution of corticotectal projection neurons correlates with the interblob compartment in macaque striate cortex. Vis Neurosci 13:461-466.

Lowel S, Singer W (1987) The pattern of ocular dominance columns in flat-mounts of the cat visual cortex. Exp Brain Res 68:661-666.

McFadzean R, Brosnahan D, Hadley D, Mutlukan E (1994) Representation of the visual field in the occipital striate cortex. Br J Ophthalmol $78: 185-190$

Menon RS, Ogawa S, Strupp JP, Ugurbil K (1997) Ocular dominance in human V1 demonstrated by functional magnetic resonance imaging. J Neurophysiol 77:2780-2787.

Moon C-H, Fukuda M, Park S-H, Kim S-G (2007) Neural interpretation of blood oxygenation level-dependent fMRI maps at submillimeter columnar resolution. J Neurosci 29:6892-6902.

Murphy KM, Jones DG, Van Sluyters RC (1995) Cytochrome-oxidase blobs in cat primary visual cortex. J Neurosci 15:4196-4208.

Obermayer K, Blasdel GG (1993) Geometry of orientation and ocular dominance columns in monkey striate cortex. J Neurosci 13:4114-4129.

Olavarria JF, Van Sluyters RC (1985) Unfolding and flattening the cortex of gyrencephalic brains. J Neurosci Methods 15:191-202.

Popoff N (1927) Zur Kenntnis der Grösse der Area striate und die Methodik ihrer Ausmessung. J Psychol Neurol 34:238-242.

Putnam T (1926) Studies on the central visual connections. III. The general relationships between the external geniculate body, optic radiations and visual cortex in man. Report of two cases. Archs Neurol Psychiat Lond 16:683-707.

Rosa MG, Gattass R, Fiorani Júnior M (1988) Complete pattern of ocular dominance stripes in V1 of a New World monkey, Cebus apella. Exp Brain Res 72:645-648.
Sasaoka M, Hara H, Nakamura K (2005) Comparison between monkey and human visual fields using a personal computer system. Behav Brain Res 161:18-30.

Schwartz EL (1994) Computational studies of the spatial architecture of primate visual cortex. In: Primary visual cortex in primates (Peters A, Rockland KS, eds), pp 359-411. New York: Plenum.

Sereno MI, Dale AM, Reppas JB, Kwong KK, Belliveau JW, Brady TJ, Rosen BR, Tootell RB (1995) Borders of multiple visual areas in humans revealed by functional magnetic resonance imaging. Science 268:889-893 .

Shipp S, Zeki S (1985) Segregation of pathways leading from area V2 to areas V4 and V5 of macaque monkey visual cortex. Nature 315:322-325.

Shmuel A, Yacoub E, Chaimow D, Logothetis NK, Ugurbil K (2007) Spatiotemporal point-spread function of fMRI signal in human gray matter at 7 Tesla. NeuroImage 35:539-552.

Sincich LC, Horton JC (2002) An albino-like decussation error in the optic chiasm revealed by anomalous ocular dominance columns. Vis Neurosci 19:541-545.

Sincich LC, Adams DL, Horton JC (2003) Complete flatmounting of the macaque cerebral cortex. Vis Neurosci 20:663-686.

Stensaas SS, Eddington DK, Dobelle WH (1974) The topography and variability of the primary visual cortex in man. J Neurosurg 40:747-755.

Swindale NV (1988) Role of visual experience in promoting segregation of eye dominance patches in the visual cortex of the cat. J Comp Neurol 267:472-488

Tootell RB, Silverman MS (1985) Two methods for flat-mounting cortical tissue. J Neurosci Methods 15:177-190.

Tootell RB, Taylor JB (1995) Anatomical evidence for MT and additional cortical visual areas in humans. Cereb Cortex 1:39-55.

Tootell RB, Silverman MS, De Valois RL, Jacobs GH (1983) Functional organization of the second cortical visual area in primates. Science 220:737-739.

Tootell RB, Switkes E, Silverman MS, Hamilton SL (1988) Functional anatomy of macaque striate cortex. II. Retinotopic organization. J Neurosci 8:1531-1568.

Van Essen DC, Newsome WT, Maunsell JH (1984) The visual field representation in striate cortex of the macaque monkey: asymmetries, anisotropies, and individual variability. Vision Res 24:429-448.

Wiesel TN, Hubel DH, Lam DMK (1974) Autoradiographic demonstration of ocular-dominance columns in the monkey striate cortex by means of transneuronal transport. Brain Res 79:273-279.

Wong AM, Sharpe JA (1999) Representation of the visual field in the human occipital cortex: a magnetic resonance imaging and perimetric correlation. Arch Ophthalmol 117:208-217.

Wong-Riley MTT (1979) Changes in the visual system of monocularly sutured or enucleated cats demonstrable with cytochrome oxidase histochemistry. Brain Res 171:11-28.

Xu X, Bosking WH, White LE, Fitzpatrick D, Casagrande VA (2005) Functional organization of visual cortex in the prosimian bush baby revealed by optical imaging of intrinsic signals. J Neurophysiol 94:2748-2762.

Zhao F, Wang P, Hendrich K, Kim SG (2005) Spatial specificity of cerebral blood volume-weighted fMRI responses at columnar resolution. NeuroImage 27:416-424. 